J. Lake Sci. (湖泊科学), 2021, 33(3): 893-904

DOI 10. $18307 / 2021.0323$

(c) 2021 by Journal of Lake Sciences

\title{
黄河中游小北干流段持续淤积期的主槽摆动特点”
}

\author{
余铖峥, 夏军强**, 周美蓉, 邓珊珊, 王英珍 \\ (武汉大学水资源与水电工程科学国家重点实验室,武汉 430072)
}

\begin{abstract}
摘 要: 黄河中游小北干流河段为典型的游荡型河段,主槽经常发生摆动,揭示主槽摆动特点对研究该河段的河床演变 规律具有重要意义. 以 1986-2001 年小北干流段汛后卫星遥感资料与实测 29 个淤积大断面地形资料为基础,计算了断 面及河段尺度的主槽摆动宽度与强度, 定量分析了持续淤积期小北干流段的主槽摆动特点及其主要影响因素. 计算结果 表明: 主槽摆动方向具有往复性, 断面主槽摆动宽度沿程变化表现为上段大、中下两段小的特点, 其中禹门口一庙前段多 年平均主槽摆动宽度和强度分别为 $1151 \mathrm{~m} / \mathrm{a}$ 和 0.70 , 是小北干流段中主槽摆动最为剧烈的河段; 建立了小北干流段主槽 摆动强度与上游水沙条件 (来沙系数) 与下游侵蚀基准面 (潼关高程) 之间的单因素及多因素响应关系, 并对综合关系式 进行了率定与验证. 在综合关系式中, 主槽摆动强度随来沙系数和潼关高程的增大而增大, 且两者在该关系式中的占比 平均值分别为 $89.3 \%$ 和 $10.7 \%$, 说明水沙条件是影响黄河中游小北干流段主槽摆动强度的主要因素,潼关高程是次要因 素. 采用该经验公式得到的计算值与实测值总体符合较好,可用于计算和预测小北干流段持续淤积期的主槽摆动过程. 关键词: 主槽摆动;遥感影像;潼关高程;水沙条件;黄河小北干流
\end{abstract}

\section{Characteristics of main-channel migration in the Xiaobeiganliu reach of the middle Yellow River during the continuous siltation period*}

\author{
Yu Chengzheng, Xia Junqiang ** , Zhou Meirong, Deng Shanshan \& Wang Yingzhen \\ ( State Key Laboratory of Water Resources and Hydropower Engineering Science, Wuhan University, Wuhan 430072, P.R.Chi- \\ na)
}

\begin{abstract}
The Xiaobeiganliu reach of the middle Yellow River is a braided reach, and the main-channel of this reach often migrates, so investigating the characteristics of main-channel migration is crucial to understand the river regime adjustments and fluvial processes of the Xiaobeiganliu reach. In this study, main-channel migration widths and intensities at section- and reach-scales were calculated based on post-flood remote sensing images and 29 observed cross-sectional profiles in the Xiaobeiganliu reach during the period from 1986 to 2001, in order to investigate the characteristics of main-channel migration and to analyze the influencing factors of main-channel migration intensities quantitatively. Calculated results indicate that: ( $i$ ) the main-channel migration processes were reciprocating, and section-scale main-channel migration widths in the upper reach were larger than those in the middle and lower reaches; ( ii ) the width and intensity of main-channel migration of the Yumenkou-Miaoqian reach were $1151 \mathrm{~m} / \mathrm{a}$ and 0.70 , respectively, and it was the most dramatic reach in terms of the main-channel migration in the Xiaobeiganliu reach; ( iii ) the main-channel migration intensity can be represented by empirical functions of two key hydrodynamic parameters, covering the upstream boundary condition ( the previous three-year average incoming sediment coefficient), and the downstream boundary condition ( the variation in Tongguan elevation); (iv ) higher values of incoming sediment coefficient and Tongguan elevation caused a larger main-channel migration intensity, which contribute about $89.3 \%$ and $10.7 \%$, respectively, and it indicates that the incoming flow and sediment regime is the dominant factor affecting the main-channel migration in the Xiaobeiganliu reach, and the Tongguan elevation is the secondary factor; and $(v)$ it is verified that the calculated main-channel migration by using the empirical equation agreed well with the observed data, so the empirical equation can be used to calculate and predict the processes of the main-channel migration in the Xiaobeiganliu reach during the continuous siltation period.
\end{abstract}

* 2020-03-20 收稿;2020-07-19 收修改稿.

国家自然科学基金项目 (51725902,51579186) 和国家重点研发计划项目 (2017YFC0405501) 联合资助.

** 通信作者;E-mail: xiajq@whu.edu.cn. 
Keywords: Main-channel migration; remote sensing images; Tongguan elevation; flow and sediment regime; Xiaobeiganliu reach of the middle Yellow River

小北干流河段具有“宽浅散乱”及主流摆动频繁等特点, 且该河段河床淤积抬升严重,河势游荡剧烈, 是 黄河中游最难治理的河段之一.上游来水来沙条件、下游侵蚀基准面条件、河床边界条件以及水库调水调沙 方式的改变都会引起小北干流段河床形态的调整 ${ }^{[1]}$. 1986 年以后, 龙羊峡和刘家峡水库实施联合调度导致 上游来水来沙条件发生变化, 三门峡水库运用方式的改变加上潼关高程 (潼关断面 $1000 \mathrm{~m}^{3} / \mathrm{s}$ 流量对应的水 位) 升降等各类影响因素的作用, 使得小北干流段持续淤积期的河床调整特点发生了改变. 但已有成果多为 研究小北干流段的冲淤演变特点, 对主槽摆动方面的研究较少 ${ }^{[2]}$. 因此, 研究黄河中游小北干流段的主槽摆 动特点, 不仅有助于全面掌握小北干流段的河床演变规律, 也能为该河段的河势规划和河道整治提供相关 参数.

主槽又称为中水河槽, 一般定义将深槽 (枯水河槽) 和嫩滩合称为主槽 ${ }^{[3]}$. 各断面主槽中心点的连线即 为主槽中心线, 主槽中心线的摆动具有复杂的时空变化特点, 是冲积河流横向摆动的重要方面 ${ }^{[4-5]}$. 以往对 主槽摆动的研究多是依据实测水文资料及河道地形资料,通常研究方法有主流线摆幅法和测验断面确定法. 例如, 郭秀吉等 ${ }^{[2]}$ 通过统计黄河小北干流段多年的河势资料对其主流线调整规律进行了研究, 发现主流线 与来水来沙条件及工程节点之间存在密切关系, 主流线的调整滞后于水沙变化, 且主流线摆动幅度与水沙 量之间具有幂函数关系, 当工程节点对河道限制作用越强时, 幂函数关系就越弱. 许烔心等 ${ }^{[6]}$ 以主流线带宽 度和其年摆幅作为定量指标研究了黄河下游游荡段的主槽摆动特点, 发现主流线摆动的幅度和速率既受到 水流条件的影响, 也受到边界条件的制约. 岳志春等 ${ }^{[7]}$ 采用河段地形图测绘及大断面套绘的方法对黄河宁 夏段的主槽摆动宽度进行了计算, 建立了滩槽高差与主槽摆动宽度的关系, 发现滩槽高差越大, 主槽摆动宽 度越小, 河势越难摆动. 但这些研究方法存在实测资料有限, 断面间距偏大等问题使得主槽摆动的计算精度 并不高.

而 MacDonald 等 ${ }^{[8]}$ 则采用航空照片与地图相结合的方法, 分析了明尼苏达州 16 条河流的主槽摆动规 律, 并且建立了主槽摆动宽度与水深、流量以及河床纵比降之间的函数关系, 发现主槽摆动宽度随水深与流 量的增大而减小, 而与河床纵比降之间没有相关性. Shields 等 ${ }^{[9]}$ 采用遥感影像资料和地图资料计算了 Fort Peck 大坝运行前后密苏里河的平均主槽摆动率, 发现水库运行后河道中心线变长, 且平均主槽摆动率从 6.6 $\mathrm{m} / \mathrm{a}$ 减小到 $1.8 \mathrm{~m} / \mathrm{a}$. 王英珍等 ${ }^{[10]}$ 采用遥感资料对小浪底水库运用后黄河下游游荡段的主槽摆动特点进行 了研究, 并且定量分析了水沙条件与河床边界条件对主槽摆动的影响. 这些采用遥感资料对主槽摆动研究 的方法提高了计算的精度. 但所有这些工作均只研究水沙条件或河床边界条件等单因素对主槽摆动的影 响, 而对其随上下游边界条件变化共同作用的响应关注较少, 因此有必要定量研究上游不同水沙条件和下 游侵蚀基准面 (潼关高程) 变化对小北干流主槽摆动的综合影响.

本文以小北干流段卫星遥感资料、实测断面地形资料以及水沙资料为基础, 分析小北干流段持续淤积 期的主槽摆动特点, 建立主槽摆动强度与来水来沙条件和潼关高程变化之间的单因素及多因素关系, 并定 量分析水沙条件和潼关高程变化对小北干流段主槽摆动强度的影响.

\section{1 研究河段概况}

\section{1 小北干流河段简介}

小北干流段位于黄河中游禹门口至潼关之间, 是一条具有典型堆积特性的游荡型河道. 河道全长约 $132.5 \mathrm{~km}$, 平均河宽 $8.5 \mathrm{~km}$. 该河段设有 29 个淤积测量断面及龙门、潼关 2 个水文站 (图 1). 小北干流段河 身较为顺直, 平均曲折系数 1.04. 河道平面形态呈两头宽, 中间窄的扁担状, 河床组成较粗, 且该河段河床极 为宽浅, 河道流势散乱, 洲滩密布, 汉道串沟交织, 主流左右摆动频繁 ${ }^{[11]}$.

小北干流河段根据其地形地貌特征及河道特性可分为 3 段 ${ }^{[1]}$ : (1) 禹门口 (黄淤 68) 至庙前 (黄淤 61) 段 为上段, 河长约 $42.5 \mathrm{~km}$, 河床宽度均在 $4.0 \mathrm{~km}$ 以上, 左岸有汾河汇人, 右岸有涺水河等支流汇人; (2) 庙前至 夹马口 (黄淤 54) 段为中段, 河长约 $30 \mathrm{~km}$, 河宽在 3.5 6.6 km 范围内变化, 为全河段最窄, 且两岸有第三纪 


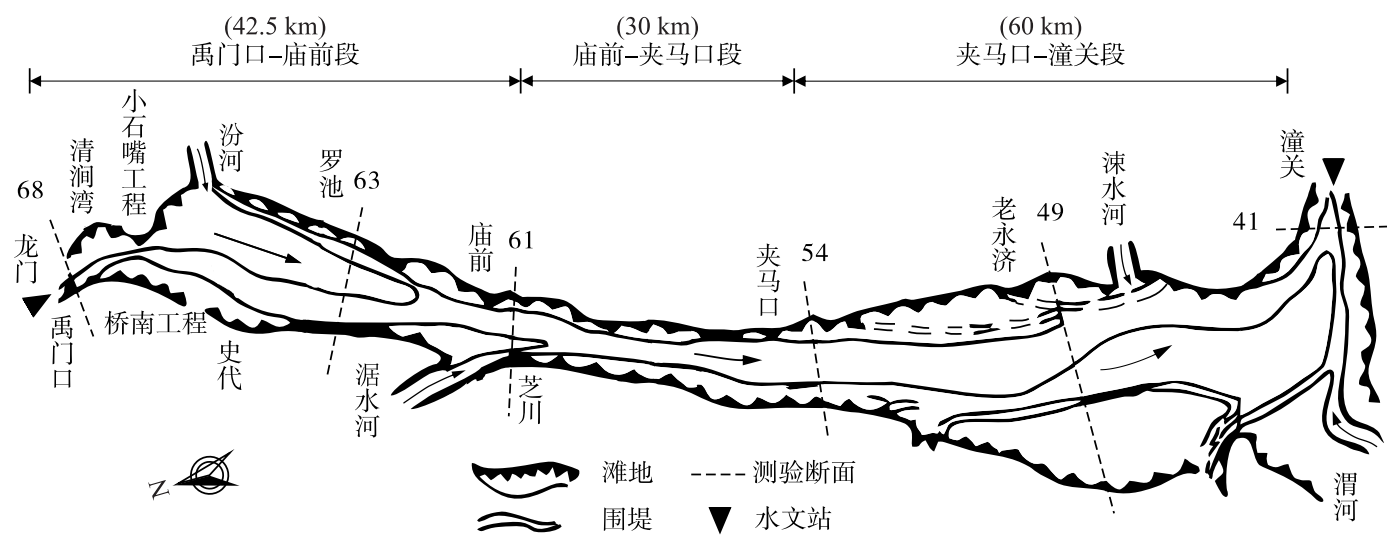

图 1 黄河小北干流段示意图

Fig.1 Sketch of the Xiaobeiganliu reach of the Yellow River

红土层出露, 抗冲能力较强, 河势较为稳定; (3)夹马口至潼关 (黄淤 41) 段为下段, 河长约 $60 \mathrm{~km}$, 平均宽度达 到 $10 \mathrm{~km}$,是小北干流段最宽的河段,渭河、涑水河在该河段汇人.

\section{2 水沙条件及河床冲淤过程}

1986 年以后, 龙羊峡水库开始投人运用, 并与刘家峡水库实施联合调度, 改变了龙门站径流量在年内的 分配,使得小北干流段持续淤积期的来水来沙特点发生了大幅度变化 ${ }^{[12-13]}$, 河床演变特点也随之改变.

龙门站是小北干流段的进口水文站, 从 1986-2015 年进人小北干流段的水量和沙量的逐年变化过程 (图 2a) 可以看出,1986-2002 年,小北干流段来水量呈减小趋势, 该时期多年平均来水量约为 197.8 亿 $\mathrm{m}^{3}$, 汛期 ( 7-10 月) 来水量占全年来水量的 $41 \% ; 2003-2015$ 年, 进人小北干流段的多年平均来水量约为 193.6 亿 $\mathrm{m}^{3}$, 汛期来水量占全年来水量的 43\%. 从来沙量 (图 2b) 来看, 1986-2002 年小北干流段的来沙量较大, 多年平均来沙量约为 4.66 亿 $\mathrm{t}$, 汛期来沙量占全年的 $81 \% ; 2003-2015$ 年, 多年平均来沙量约为 1.20 亿 $\mathrm{t}$, 汛 期来沙量占全年的 $81 \%$. 由此可见, 2002 年之后, 小北干流段的上游来水量变幅不大, 而来沙量却大幅度减 少, 减少幅度为 $67.8 \%$, 这种水沙变化特点对河道输沙和减淤有利. 1986-2015 年汛期来沙量的占比均达到 $80 \%$ 以上, 说明泥沙主要集中在汛期输送.
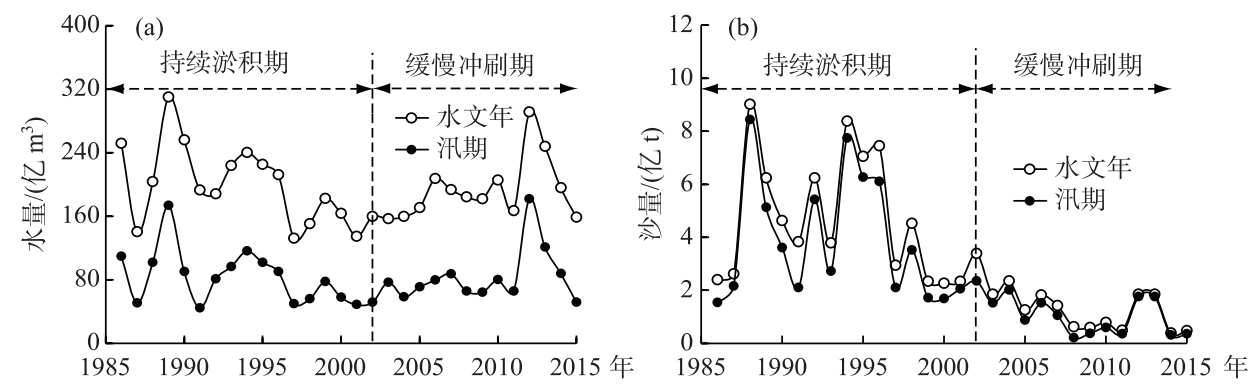

图 2 小北干流段来水来沙变化

Fig. 2 Temporal variations in the flow and sediment regime entering the Xiaobeiganliu reach

图 3 点绘了小北干流段 1986-2015 年的累计冲淤过程及相应的历年汛后潼关高程的变化情况. 如图 3 所示, 根据河床冲淤过程、进口水沙条件、潼关高程变化及水库运用情况 ${ }^{[14]}$, 黄河中游小北干流段 $1986-$ 2015 年的冲淤过程可分为 2 个阶段: (1)1986-2002 年为持续淤积期, 三门峡水库采用蓄清排浑的运用方式. 该时段上游来水来沙搭配不协调, 在三门峡水库非汛期蓄水位进一步降低的情况下,潼关高程持续抬升, 小 北干流段发生持续淤积, 累计淤积量为 7.10 亿 $\mathrm{m}^{3}$, 年均淤积 0.418 亿 $\mathrm{m}^{3} / \mathrm{a}$; 222003-2015 年为缓慢冲刷期, 
三门峡水库采用非汛期 $318 \mathrm{~m}$ 控制运用, 汛期平水期 $305 \mathrm{~m}$ 控制运用. 该时段上游来沙量大幅度减少, 在相 对有利的水沙条件和潼关高程下降的共同作用下, 小北干流段发生缓慢冲刷, 累计冲刷量为 3.09 亿 $\mathrm{m}^{3}$, 年 均冲刷 0.238 亿 $\mathrm{m}^{3} / \mathrm{a}$.

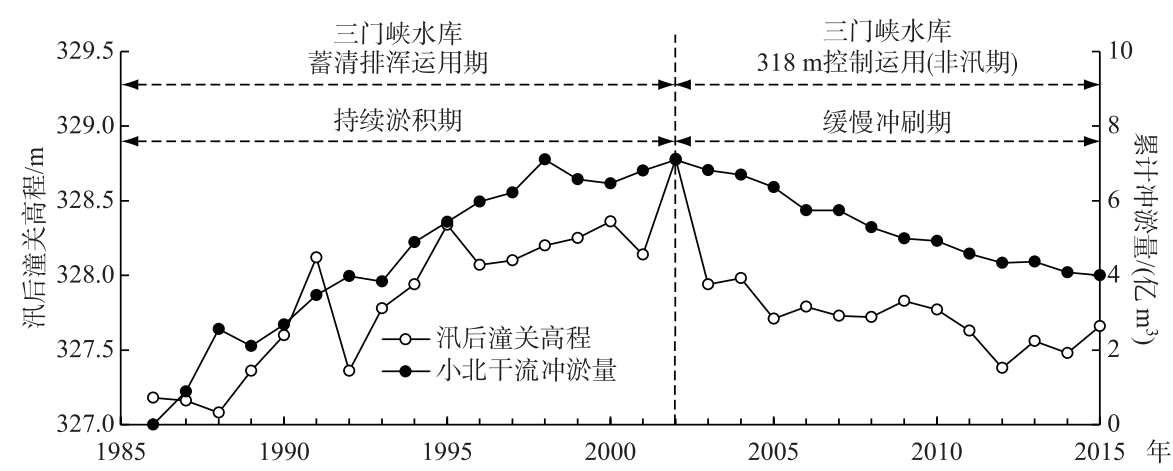

图 3 1986-2015 年小北干流段累计冲淤过程及汛后潼关高程的变化

Fig.3 Cumulative channel evolution volume in the Xiaobeiganliu reach and variation in the post-flood Tongguan elevation during the period from 1986 to 2015

\section{2 主槽摆动与水沙条件的计算方法}

\section{1 主槽摆动宽度与强度的计算方法}

主槽摆动宽度和强度的计算方法, 主要分为 3 个步骤: (1)根据当年及上一年汛后遥感影像资料确定各 个断面的主槽摆动宽度; 2根据当年及上一年汛后实测断面地形资料,确定各淤积断面的平滩河宽; (3)采用 基于对数转换的几何平均与断面间距加权平均相结合的方法,计算河段尺度的平滩河宽、主槽摆动宽度和 强度.

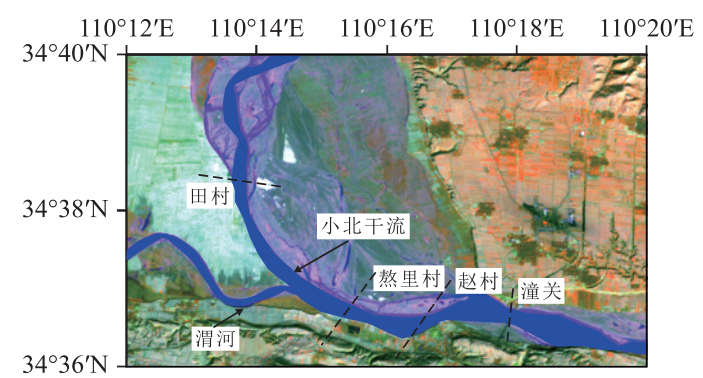

图 41988 年汛后潼关断面附近的局部遥感影像图

Fig.4 Local remote sensing image near the

Tongguan section after the 1988 flood season
2.1.1 断面尺度主槽摆动宽度的计算 遥感影像是指 记录各种地物电磁波大小的胶片或照片, 主要包括航 空像片和卫星相片 ${ }^{[15]}$. 本研究采用的遥感影像资料 来源于美国地质勘探局 (USGS), 其免费提供 NASA Landsat 系列卫星的所有遥感数据. 该系列卫星数据 具有下载存档方便、时间序列长、观测覆盖面积广等 优点. 与以往采用断面地形资料的方法相比, 采用遥 感影像资料不仅可以较好地勾绘出河道平面形态, 而 且具有能够直观清晰地分辨出水体与陆地的分界线 等优点 (图 4); 再与地理信息系统相结合, 可以将不 同时段的遥感影像资料统一进行对比分析, 从而得到 长时间序列的主槽摆动特点, 大大提高了计算的精

度. 故采用遥感技术与地理信息系统相结合的方法研究小北干流段主槽摆动特点具有重要意义 ${ }^{[16]}$.

游荡型河段汛期来水量非常大, 且易发生漫滩洪水,较难区分主槽与滩地区域; 而汛后流量减少, 河道 水位较低, 能确保主槽位置提取的精度, 故此处选用汛后遥感影像资料进行研究. 2002 年之后小北干流段处 于缓慢冲刷期, 上游来沙量大幅度减少, 河势也较为稳定; 而在 2002 年之前的持续淤积期, 河床持续淤积, 河势摆动频繁,故此处仅对小北干流段持续淤积期的主槽摆动特点进行研究. 选用 1986- 2001 年汛后 $30 \mathrm{~m}$ 分辨率的卫星遥感影像资料 (Landsat-4、5 系列), 从中提取非汛期主槽两侧的水边线, 具体处理步骤可参考 相关文献 ${ }^{[10]}$.

处理完遥感影像后, 编写出相应的 Fortran 程序对主槽水边线进行处理, 导人提取到的坐标, 计算出主槽 
左右两侧水边线与各划分断面的交点 $\left(X_{\mathrm{iL}}, Y_{\mathrm{iL}}\right) 、\left(X_{\mathrm{iR}}, Y_{\mathrm{iR}}\right)$, 如图 5a 中标记所示; 然后用左右两交点求出各 断面中心点即为主槽中心线所在位置的坐标 $\left(X_{\mathrm{iC}}, Y_{\mathrm{iC}}\right)$, 相邻两年各断面主槽中心线之间的距离即为主槽摆 动宽度 $\Delta B$ (图 5b). 采用水边线中点作为主槽中心的误差主要存在于遥感影像处理到数字水边线的提取过 程, 且主要为提取矢量水边线过程中产生的数字化误差 ${ }^{[17-18]}$. 此处采用目视解译的方法提取水边线, 且所有 数字化工作由一人完成, 保证了计算的精度.
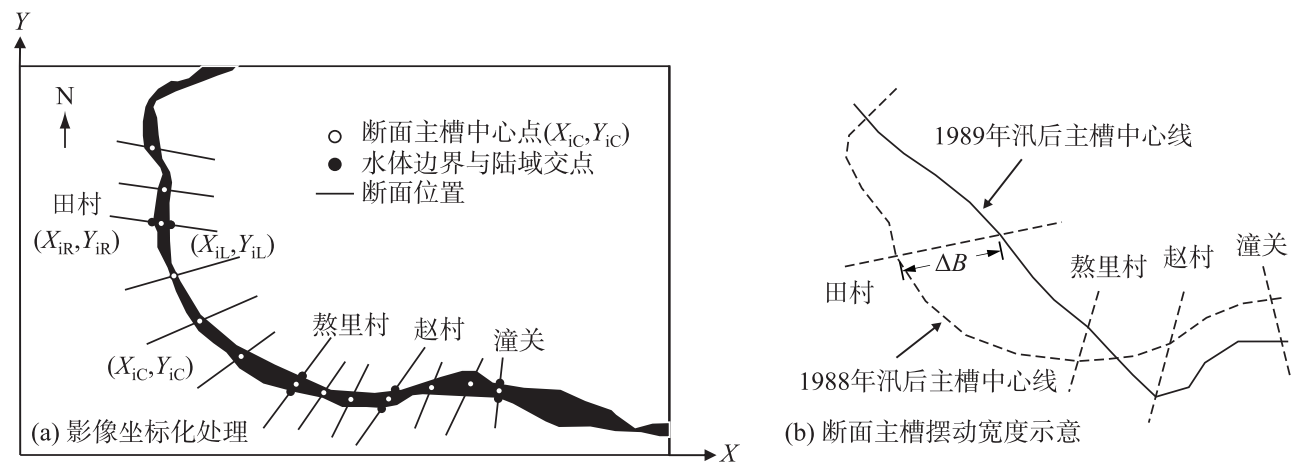

图 5 断面尺度主槽摆动宽度的计算方法

Fig.5 Method for determining the section-scale main-channel migration width

\subsection{2 断面及河段尺度平滩河宽的计算 1) 断面尺度平滩河宽的计算}

由于在遥感影像中平滩水位不易确定, 故不能采用上述处理方法来确定各断面的平滩河宽 $(W)$, 而只 能用实测断面地形资料来确定滩地范围. 故此处采用 1986- 2001 年小北干流段 29 个淤积实测大断面地形 资料, 确定每年汛后各个断面的平滩河宽, 具体确定原则可参考相关文献 ${ }^{[19]}$.

2) 河段尺度平滩河宽的计算

游荡型河段相邻各断面之间并不是等间距划分的, 为避免断面间距不相等对计算结果造成影响, 采用 基于对数转换的几何平均与断面间距加权平均相结合的方法来计算河段尺度的平滩河宽 ${ }^{[20]}$ :

$$
\bar{W}=\exp \left(\frac{1}{2 L_{1}} \sum_{i=1}^{N_{1}-1}\left(\ln \left(W_{i}\right)+\ln \left(W_{i+1}\right)\right) \Delta x_{i}\right)
$$

式中, $\bar{W}$ 为河段尺度的平滩河宽, $\mathrm{m} ; W_{i} 、 W_{i+1}$ 为第 $i 、 i+1$ 断面的平滩河宽, $\mathrm{m} ; N_{1}$ 为河段内淤积断面数量; $\Delta x_{i}$ 为相邻两断面 $(i, i+1)$ 的间距; $L_{1}$ 为基于水文部门确定的研究河段总长度.

2.1.3 河段尺度主槽摆动宽度及强度的计算 与计算河段尺度平滩河宽类似,采用上述河段平均的方法计算 河段尺度主槽摆动宽度：

$$
\Delta \bar{B}_{\mathrm{mc}}=\exp \left(\frac{1}{2 L_{2}} \sum_{k=1}^{N_{2}-1}\left(\ln \left(\Delta B_{\mathrm{mc}}^{k}\right)+\ln \left(\Delta B_{\mathrm{mc}}^{k+1}\right)\right) \Delta l_{k}\right)
$$

式中, $\Delta \bar{B}_{\mathrm{mc}}$ 为河段尺度的主槽摆动宽度, $\mathrm{m} ; \Delta B_{\mathrm{mc}}^{k} 、 \Delta B_{\mathrm{mc}}^{k+1}$ 为第 $k 、 k+1$ 断面的主槽摆动宽度, $\mathrm{m} ; N_{2}$ 为河段内划 分的断面数量; $\Delta l_{k}$ 为相邻两断面 $(k, k+1)$ 主槽中心线的间距; $L_{2}$ 为基于遥感资料确定的研究河段总长度.

对于游荡型河段来说, 河床较为宽浅,为了更好地反映河段主槽摆动的剧烈程度, 此处引人一个无量纲 参数主槽摆动强度 $M_{\mathrm{mc}}$ 作为主槽摆动的特征指标：

$$
M_{\mathrm{mc}}=\frac{\Delta \bar{B}_{\mathrm{mc}}}{\left(\bar{W}_{1}+\bar{W}_{2}\right) / 2}
$$

式中, $\bar{W}_{1} 、 \bar{W}_{2}$ 分别为当年及上一年河段尺度的平滩河宽, $\mathrm{m}$. 主槽摆动强度 $M_{\mathrm{mc}}$ 越大, 说明河段摆动越为剧 烈. 已有研究表明研究河段内划分的断面数量越多, 则计算结果越准确, 精度越高, 越能反映河道的整体情 况,故此处在小北干流段中划分了 137 个加密断面,接近 $1 \mathrm{~km}$ 一个断面,保证了计算结果的精度.

\section{2 水沙条件的计算方法}

上游来水来沙条件主要是指一定时期河段上游的来水量、来沙量、来沙组成及其变化过程. 此处采用年 
均水流冲刷强度 $F_{i}$ 以及来沙系数 $\xi_{i}$ 来表征来水来沙条件, 年均水流冲刷强度即:

$$
F_{i}=\left(\bar{Q}_{i}^{2} / \bar{S}_{i}\right) / 10^{4}
$$

式中, $\bar{Q}_{i}$ 为第 $i$ 年的平均流量, $\mathrm{m}^{3} / \mathrm{s} ; \bar{S}_{i}$ 为第 $i$ 年的平均含沙量, $\mathrm{kg} / \mathrm{m}^{3}$. 来沙系数 $\xi_{i}$ 即为平均含沙量与平均 流量的比值: $\xi_{i}=S_{i} / Q_{i}$. 冲积河流在冲淤平衡的状态下, 某一断面的输沙率 $Q_{\mathrm{s}}$ 与流量 $Q$ 之间常存在一定的 经验关系, 且可表示为 $Q_{\mathrm{s}}=a Q^{b}$, 其中 $a$ 为系数, $b$ 为指数, 且 $b$ 一般可取 $2.0^{[21]}$. 因此 $F_{i}$ 计算式中 $\bar{Q}_{i}^{2}$ 可近似 代表该断面的水流挟沙能力, 而特定流量下挟沙力与含沙量的比值则用 $\bar{Q}_{i}^{2} / \bar{S}_{i}$ 来表示.

考虑到河床形态调整存在滞后响应现象 ${ }^{[22]}$, 定义前期水沙条件用前 $n$ 年平均水流冲刷强度 $\bar{F}_{n}$ 表示:

$$
\bar{F}_{n}=\frac{1}{n} \sum_{i=1}^{n} \bar{F}_{i}
$$

式中, $\bar{F}_{i}$ 为第 $i$ 年平均水流冲刷强度. 游荡段主槽摆动强度则可以表示为 $\bar{F}_{n}$ 的经验函数.

\section{3 小北干流段持续淤积期的主槽摆动特点}

采用上述方法,分别对小北干流段持续淤积期(1986-2001 年) 断面及河段尺度的主槽摆动方向、摆动 宽度以及河段尺度主槽摆动强度进行统计. 下面将从这几个方面对小北干流段持续淤积期的主槽摆动特点 进行详细分析.

\section{1 主槽摆动方向}

小北干流河道自上而下由禹门口、庙前、夹马口和潼关 4 个断面将其划分为 3 段, 因此本研究以这 4 个 典型断面为例, 统计 1986-2001 年这些断面主槽摆动方向的变化. 定义当年断面主槽中心点相较于上一年 向左岸摆动为左摆, 向右岸摆动为右摆; 左右摆动比例为当年主槽左摆断面数与右摆断面数的比值. 统计结 果表明:在这期间, 禹门口、庙前、夹马口和潼关断面左摆次数分别为 $7 、 5 、 5 、 8$ 次,右摆次数分别为 $8 、 10 、 10$ 、 7 次. 说明在持续淤积期, 禹门口与潼关断面主槽向左与向右摆动的概率基本一致, 而庙前和夹马口断面主 槽向右摆动的次数较多.

此外还统计了 1986- 2001 年小北干流段 137 个加密断面主槽的平均摆动次数, 统计结果表明: 禹门 口一庙前段布设有 33 个加密断面, 多年平均左摆断面数为 14 , 右摆断面数为 19 ; 庙前一夹马口段布设有 41 个加密断面, 多年平均左摆断面数为 21 , 右摆断面数为 20 ; 夹马口一潼关段布设有 63 个加密断面, 多年平均 左摆断面数为 31 , 右摆断面数为 $32 ; 3$ 个分河段的主槽左右摆动比例分别为 $0.74 、 1.05$ 和 0.97 . 整个河段多 年平均左摆断面数为 66 , 右摆断面数为 71 , 左右摆动比例为 0.93 . 同时还点绘了小北干流段历年的主槽摆 动比例变化曲线 (图 6), 结合统计结果与图 6 可以得出: 1)尽管每一年的主槽左右摆动比例差异较大,但从 长时间序列来看, 主槽向左岸或右岸摆动的概率基本相当, 可表明主槽摆动方向具有往复性,也充分体现了 天然冲积河流的自动调整作用 ${ }^{[23]}$; 2)从图 $6 \mathrm{~b}$ 可以看出禹门口一庙前段左右摆动比例变化较大,说明该段河 势摆动剧烈, 主槽左右摆动频繁.
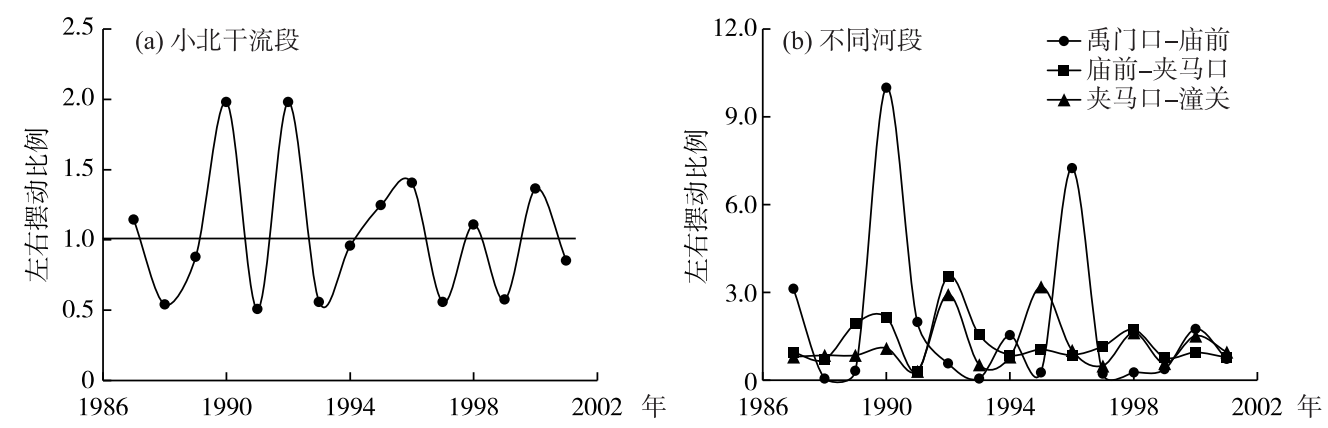

图 6 小北干流段主槽左右摆动比例变化

Fig.6 Temporal variations in the proportion of main-channel migration direction in the Xiaobeiganliu reach 


\section{2 主槽摆动宽度}

由 1986-2001 年小北干流段 4 个典型断面禹门口、庙前、夹马口和潼关的主槽摆动宽度 (图 7a) 可以看 出: 庙前断面的主槽摆动宽度明显大于其他 3 个断面, 且摆动宽度最大值发生在 1997 年, 达到 $4401 \mathrm{~m}$. 其原 因是 1994 年河津小石嘴阻水工程拆除, 对河势的影响较大, 经常有左右两条不同的流路, 1996 年主槽偏向 左岸, 水流经庙前下行, 1997 年主槽偏向右岸, 水流经史代、芝川下行 ${ }^{[24]} .4$ 个断面多年平均主槽摆动宽度分 别为 $352 、 712 、 378 、 141 \mathrm{~m} / \mathrm{a}$. 可见该河段首尾两端的主槽摆动幅度较小, 原因是禹门口与潼关是该河段的重 要节点, 断面较为窄深, 限制了河道的横向摆动. 禹门口至庙前段河势非常散乱, 主流频繁摆动, 因此庙前断 面多年平均主槽摆动宽度较大.

此外还统计了 1986-2001 年小北干流段所有断面的多年平均主槽摆动宽度, 如图 7b 所示. 统计结果 表明:在 1986- 2001 年期间,多年平均主槽摆动宽度最大值为 $1626 \mathrm{~m} / \mathrm{a}$, 发生在清涧湾断面处. 其原因是黄 河出禹门口后有两条流路, 一条是出禹门口后靠左岸直人清涧湾, 另一条则是出禹门口后主流急折向右, 流 向桥南工程 ${ }^{[24]}$; 摆动宽度最小值为 $141 \mathrm{~m} / \mathrm{a}$, 发生在潼关断面. 从沿程变化来看, 可以发现禹门口一庙前段各 断面的多年平均主槽摆动宽度较大. 图 7b 也说明小北干流段从上游到下游各断面主槽摆动宽度之间的差 异十分大, 特定几个断面的主槽摆动特点难以反映整个河段的主槽摆动规律, 故还需计算河段尺度的主槽 摆动宽度.
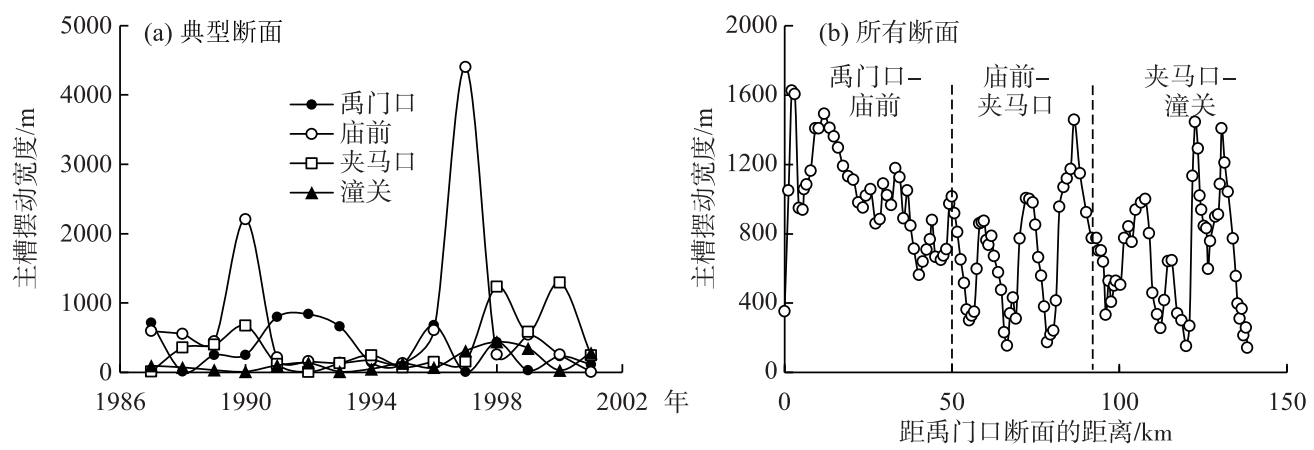

图 7 小北干流段断面尺度的主槽摆动宽度变化

Fig.7 Temporal variations in the section-scale width of main-channel migration in the Xiaobeiganliu reach

采用式 (2)计算了 1986-2001 年小北干流段河段尺度的主槽摆动宽度, 如图 8a 所示. 从图中可以看 出: 河段尺度的最大主槽摆动宽度发生在 1997 年,约为 $1144 \mathrm{~m}$; 最小主槽摆动宽度发生在 2001 年,约为 597 $\mathrm{m}$; 该时期多年平均主槽摆动宽度为 $827 \mathrm{~m} / \mathrm{a}$, 其变化趋势与小北干流段来沙量的变化趋势类似 (图 2), 可见 主槽摆动宽度的变化与上游来沙密切相关.

为进一步探讨小北干流段的主槽摆动特点,采用上述河段平均的方法计算 1986-2001 年 3个分河段的 主槽摆动宽度, 计算结果如图 $8 \mathrm{~b}$ 所示. 从分河段来看, 禹门口一庙前段的多年平均主槽摆动宽度最大, 达到 $1151 \mathrm{~m} / \mathrm{a}$, 其中 1996 年该河段的主槽摆动宽度最大, 为 $2128 \mathrm{~m}$. 庙前一夹马口, 夹马口一潼关河段多年平均 主槽摆动宽度分别为 $667 、 714 \mathrm{~m} / \mathrm{a}$. 说明小北干流段主槽摆动宽度沿程变化呈现上段大、中下两段小的 特点.

\section{3 主槽摆动强度}

采用式 (1)、式(3)计算小北干流段的主槽摆动强度,图 9a 给出了整个河段主槽摆动强度的变化过程. 主槽摆动强度最大值为 0.72 , 发生在 1997 年, 与主槽摆动宽度最大值发生的年份相同; 主槽摆动强度最小值 为 0.39 ,发生在 1991 年. 对比图 $8 \mathrm{a}$ 和图 $9 \mathrm{a}$ 可以发现,小北干流段的主槽摆动强度变化规律与主槽摆动宽度 类似.

分河段主槽摆动强度的计算结果如图 9b 所示, 结果表明: 禹门口一庙前段的多年平均主槽摆动强度为 0.70 , 庙前一夹马口段为 0.47 , 夹马口一潼关段为 0.45 ; 禹门口一庙前段多年平均主槽摆动强度在这 3 个分河 

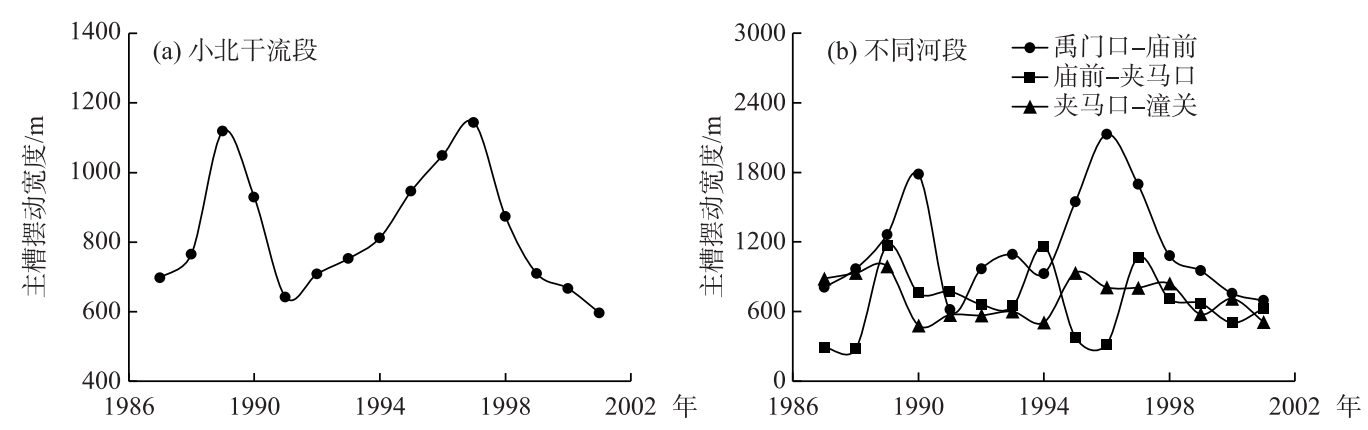

图 8 小北干流段河段尺度的主槽摆动宽度变化

Fig. 8 Temporal variations in the reach-scale width of main-channel migration in the Xiaobeiganliu reach

段中最大, 与主槽摆动宽度计算的结果一致, 说明禹门口一庙前段为小北干流河势变化最剧烈的河段, 因为 该河段斜河、横河频繁出现, 河势频繁摆动, 且汉流多, 洲滩密布, 具有 “宽浅散乱” 的特点 ${ }^{[11]}$. 庙前一夹马口 段多年平均主槽摆动强度为 0.47 , 略大于夹马口一潼关段的 0.45 , 但其多年平均主槽摆动宽度为 $667 \mathrm{~m} / \mathrm{a}$, 较 夹马口一潼关段的 $714 \mathrm{~m} / \mathrm{a}$ 小. 原因是庙前一夹马口段的平滩河宽比其他两个河段都要小, 因此计算得到的 摆动强度较大.
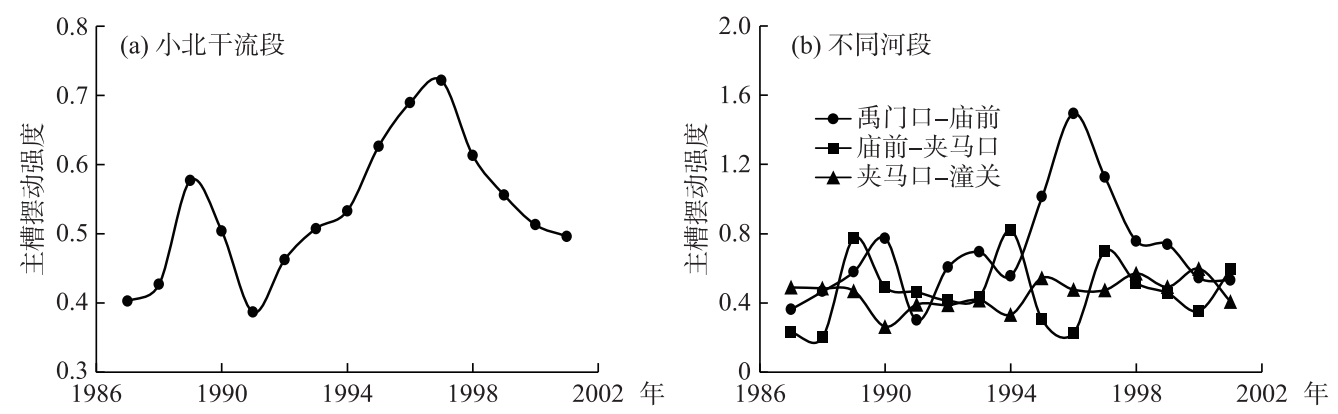

图 9 小北干流段河段尺度的主槽摆动强度变化

Fig.9 Temporal variations in the reach-scale intensity of main-channel migration in the Xiaobeiganliu reach

\section{4 小北干流段主槽摆动强度的影响因素}

天然河流的河床演变是由多方面极其复杂的因素决定的,一般包括上、下游边界条件及河床周界条件 3 个方面. 上游边界条件指的是上游来水来沙条件; 下游边界条件主要是指出口处的侵蚀基准面条件, 对于小 北干流来说, 即为潼关高程; 河床周界条件泛指河流所在河谷的地质地貌条件, 包括河谷比降、河相关系、滩 槽高差以及河漫滩组成等 ${ }^{[21,23]}$. 当上述某一类边界条件改变时, 河床将发生冲淤变形, 河槽断面形态相应调 整, 主槽位置也随之发生变化. 下面将探究来水来沙条件和潼关高程对小北干流段主槽摆动强度的影响.

\section{1 来水来沙条件的影响}

为研究上游水沙条件对主槽摆动强度的影响, 采用 1986-2001 年龙门站的水沙数据建立小北干流段主 槽摆动强度与年均流量、年均含沙量、年均来沙系数、年均水流冲刷强度的经验关系. 水流冲刷强度即采用 式 (4)、式 (5) 进行计算. 主槽摆动强度 $M_{\mathrm{mc}}$ 与年均水流冲刷强度 $\bar{F}_{n}$ 、年均含沙量 $\bar{S}_{n}$ 、来沙系数 $\bar{\xi}_{n}$ 之间的相 关程度与所考虑的年数呈抛物线关系, 根据实测水沙资料进行分析, 其相关系数均在 $n=3$ 时达到最大.

图 10 点绘了 1986-2001 年小北干流段主槽摆动强度与前 3 年平均流量、前 3 年平均含沙量、前 3 年平 均来沙系数、前 3 年平均水流冲刷强度的关系, 得到如下结论:

1) 图 10a 点据散乱, 可以看出小北干流段主槽摆动强度与单一流量因子的关系非常弱, 决定系数为 
0.07 , 接近于 0 , 说明两者几乎没有相关性;

2) 小北干流段主槽摆动强度随年均含沙量 $\bar{S}_{3}$ 的增大而增大, 决定系数为 0.49 , 说明单一来沙条件远比 单一来水条件重要, 是影响主槽摆动强度的主要因素;

3) 小北干流段主槽摆动强度随年均来沙系数 $\bar{\xi}_{3}$ 的增大而增大, 随年均水流冲刷强度 $\bar{F}_{3}$ 的增大而减小, 决定系数分别为 0.65 和 0.59 , 较考虑单一因子的决定系数均有提高, 说明来水来沙条件是影响主槽摆动强 度的主要因素, 且来沙条件的影响更为重要. 年均含沙量 $\bar{S}_{3}$ 、年均来沙系数 $\bar{\xi}_{3}$ 越小, 年均水流冲刷强度 $\bar{F}_{3}$ 越 大, 主槽摆动强度就越小, 河段游荡性也越低.
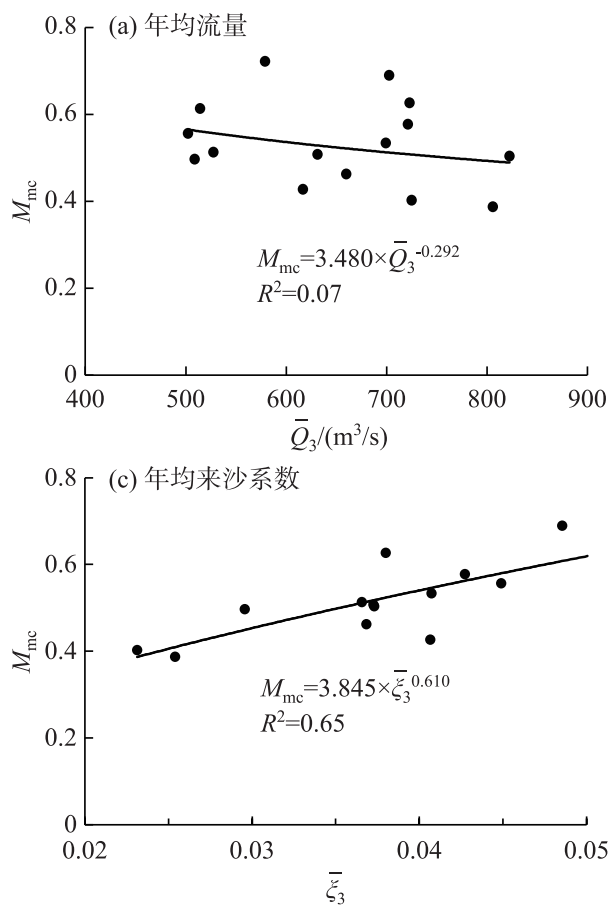
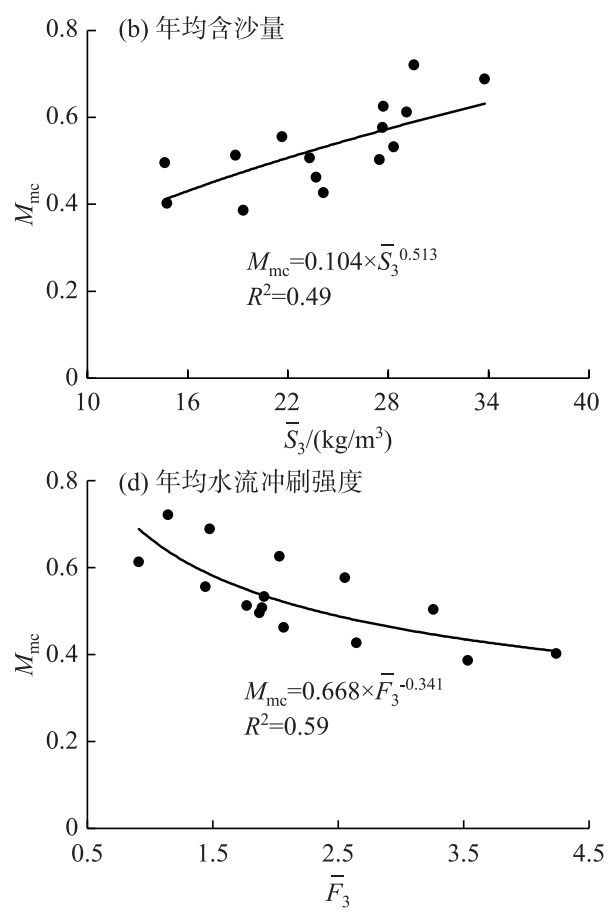

图 10 水沙条件与小北干流段主槽摆动强度的关系

Fig.10 Relationships between main-channel migration intensity of the

Xiaobeiganliu reach and flow and sediment regime

\section{2 潼关高程的影响}

潼关断面位于黄河和渭河汇流处, 即宽浅河道突然收缩进人三门峡峡谷河道的衔接处, 此处河谷宽仅 $850 \mathrm{~m}$, 形成天然卡口. 由于特殊的地理条件, 潼关高程成为小北干流河道的局部侵蚀基准面 (下游边界条 件), 对河床纵剖面的调整、冲淤变化和河势摆动都有着重要影响 ${ }^{[12-13,25]}$. 潼关高程的高低影响着小北干流 段的冲淤变化,从而对该河段的河势产生影响,也直接影响着小北干流河道形态的调整过程.

通常采用河段出口处的水位一流量关系反映侵蚀基准面条件,但实际应用时采用关系曲线确定侵蚀基 准面变化对河床演变影响的方法较为复杂 ${ }^{[26]}$. 为便于分析应用,此处采用实际潼关高程相对于 1986 年潼关 高程的变化值 $\Delta \bar{Z}$ 作为下游边界条件(潼关高程取汛前汛后平均值), 以反映出口侵蚀基准面变化对河道主 槽的塑造作用. 从主槽摆动强度与下游边界条件 $\Delta \bar{Z}$ 的相关关系可以看出主槽摆动强度 $M_{\mathrm{mc}}$ 随潼关高程的 增大而增大, 决定系数为 0.29 (图 11a), 说明潼关高程的变化对小北干流主槽摆动有一定的影响,但影响程 度较小.

\section{3 上、下游边界条件的综合影响}

为了更好地反映主槽摆动强度的变化特点, 此处考虑上、下游边界条件共同作用对主槽摆动强度的影 
响. 由前文可知主槽摆动强度与来沙系数的相关性较其与水流冲刷强度的好, 因此选用前 3 年平均来沙系 数 $\bar{\xi}_{3}$ 作为描述来水来沙条件的影响因素; 潼关高程的变化值 $\Delta \bar{Z}$ 作为描述下游边界条件的影响因素, 采用 多元回归分析的方法建立 $M_{\mathrm{mc}}$ 与 $\bar{\xi}_{3} 、 \Delta \bar{Z}$ 之间的综合关系式:

$$
M_{\mathrm{mc}}=\alpha_{1}\left(\bar{\xi}_{3}\right)^{\beta_{1}}+\alpha_{2}(\Delta \bar{Z})^{\beta_{2}}
$$

式中, $\alpha_{1} 、 \alpha_{2}$ 为系数; $\beta_{1} 、 \beta_{2}$ 为指数. 这 4 个参数需要用实测水沙资料以及前述主槽摆动强度计算值率定.

将小北干流段 1986-2001 年的数据分为 2 段, 1986-1999 年的数据用来率定式 (6) 中的参数, 20002001 年的数据用来验证公式的合理性. 利用 SPSS 软件对式 (6) 中的参数进行率定, 率定结果为: $\alpha_{1}=3.354$, $\beta_{1}=0.599, \alpha_{2}=0.071, \beta_{2}=1.419, R^{2}=0.72$. 可以看出: (1)综合考虑两个因素的影响, 经验公式的决定系数达到 0.72 , 较之前考虑单因素时的 0.65 与 0.29 均有较大幅度的提升; (2)变量 $\bar{\xi}_{3}$ 与 $\Delta \bar{Z}$ 的参数率定值 $\left(\alpha_{1} 、 \beta_{1}\right.$ 和 $\alpha_{2} 、 \beta_{2}$ ) 均为正数, 说明 $M_{\mathrm{mc}}$ 随 $\bar{\xi}_{3} 、 \Delta \bar{Z}$ 的增大而增大. (3) $\alpha_{1}\left(\bar{\xi}_{3}\right)^{\beta_{1}}$ 和 $\alpha_{2}(\Delta \bar{Z})^{\beta_{2}}$ 在式 (6) 中的占比平均值分别为 $89.3 \%$ 和 $10.7 \%$, 以 1994 年为例, 采用式 (6) 计算得到的 $M_{\mathrm{mc}}$ 为 0.549 , 其中 $\alpha_{1}\left(\bar{\xi}_{3}\right)^{\beta_{1}}$ 和 $\alpha_{2}(\Delta \bar{Z})^{\beta_{2}}$ 的值分别为 0.493 和 0.056. 综上说明小北干流段主槽摆动强度受上游来水来沙条件和潼关高程变化的相互制约, 且来 水来沙条件是影响小北干流段主槽摆动的主要因素, 潼关高程是次要因素, 二者共同影响小北干流段的主 槽摆动.

为了对式 (6) 进行验证, 图 11b 给出了小北干流段主槽摆动强度与采用式 (6)计算得到的计算值, 从图 中可以看出: $M_{\mathrm{mc}}$ 计算值与实测值符合较好, 相对误差介于 $0.76 \% \sim 16.02 \%$ 之间, 平均相对误差为 $8.53 \%$, 二 者吻合度较高. 在验证期内, $1999-2001$ 年实测的主槽摆动强度分别为 $0.51 、 0.50$, 采用式 (6) 计算得到的主 槽摆动强度分别为 $0.56 、 0.50$, 相对误差分别为 $9.7 \% 、 0.8 \%$, 平均相对误差为 $5.2 \%$. 综上说明所提出来的经 验公式 $M_{\mathrm{mc}}=3.354\left(\bar{\xi}_{3}\right)^{0.599}+0.071(\Delta \bar{Z})^{1.419}$ 可以较好地反映小北干流段主槽摆动强度的变化趋势以及主 槽摆动强度对上、下游边界条件的响应关系,并可用于预测小北干流段持续淤积期的主槽摆动过程.
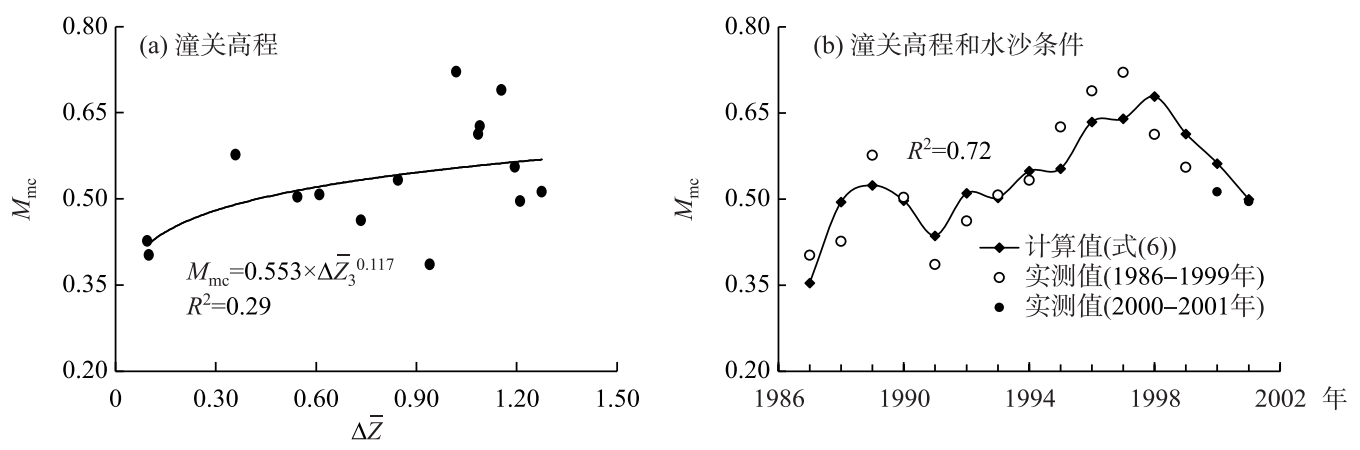

图 11 潼关高程和水沙条件与小北干流段主槽摆动强度的关系

Fig.11 Relationships between the main-channel migration intensity of the Xiaobeiganliu reach and flow and sediment regime and the variation in Tongguan elevation

\section{5 结论}

本文采用遥感影像资料与实测断面地形资料相结合的方法,对黄河中游小北干流段持续淤积期 (19862001 年) 的主槽摆动特点进行了研究,并得出以下结论：

1) 小北干流段主槽摆动方向具有往复性,主槽向左岸或右岸摆动的比例基本相当,各断面主槽摆动宽 度差异较大,沿程变化表现为上段大、中下两河段小的特点.

2) 在持续淤积阶段, 小北干流段年均主槽摆动宽度和强度分别为 $827 \mathrm{~m} / \mathrm{a}$ 和 0.53 ; 其中禹门口一庙前、 庙前一夹马口、夹马口一潼关 3 个分河段的主槽摆动宽度分别为 $1151 、 667 、 714 \mathrm{~m} / \mathrm{a}$, 摆动强度分别为 0.70 、 0.47、0.45. 从主槽摆动宽度和强度的计算结果来看, 禹门口一庙前河段是小北干流段中主槽摆动最为剧烈的 河段. 
3) 小北干流段主槽摆动强度随前 3 平均水流冲刷强度的增大而减小, 随来沙系数、含沙量以及潼关高 程的增大而增大. 建立了小北干流段主槽摆动强度与上游来水来沙条件和潼关高程之间的单因素及多因素 响应关系, 相关性较好, $R^{2}$ 值达 0.72 , 两者在该关系式中的占比平均值分别为 $89.3 \%$ 和 $10.7 \%$, 说明上游来水 来沙条件是影响小北干流段主槽摆动强度的主要因素, 潼关高程的变化是次要因素. 采用该经验公式得到 的计算值与实测值总体符合较好, 可以用来预测小北干流段持续淤积期的主槽摆动过程.

\section{6 参考文献}

[ 1 ] Jin DS, Zhang OY, Chen H et al. Analysis of thalweg evolution tendency of the wandering reach in the Lower Yellow River after Xiaolangdi Reservoir operation. Journal of Sediment Research, 2000, (6):52-62. [ 金德生, 张欧阳, 陈浩等. 小浪 底水库运用后黄河下游游荡性河段深泓演变趋势分析. 泥沙研究, 2000，(6): 52-62.]

[ 2 ] Guo XJ, Hou SZ, Wang P. Relationships between changes of the main streamline and flow and sediment regime of the Xiaobeiganliu reach of the Yellow River. China Rural Water and Hydropower, 2018, (11): 98-102. [郭秀吉, 侯素珍, 王 平. 黄河小北干流主流线变化与来水来沙的关系. 中国农村水利水电, 2018, (11) : 98-102.]

[ 3 ] Xia JQ, Wu BS, Li WW. Comparison of different approaches to determine bankfull discharge in the Lower Yellow River. Journal of Sediment Research, 2009, (3) : 20-29. [夏军强, 吴保生, 李文文. 黄河下游平滩流量不同确定方法的比 较. 泥沙研究, 2009, (3) : 20-29.]

[ 4 ] Hooke JM. Magnitude and distribution of rates of river bank erosion. Earth Surface Processes, 1980, 5(2) : 143-157. DOI: 10.1002/esp.3760050205.

[ 5 ] Lawler DM, Grove JR, Couperthwaite JS et al. Downstream change in river bank erosion rates in the Swale-Ouse system, Northern England. Hydrological Processes, 1999, 13 (7) : 977-992. DOI: 10. 1002/( SICI) 1099-1085 ( 199905 ) 13 : 7977 : : AID-HYP785>3.0.CO;2-5.

[ 6 ] Xu JX, Sun J. Tendency of channel change of the Lower Yellow River during its shrinkage. Journal of Sediment Research, 2003, (1): 10-17. [许昫心, 孙季. 黄河下游游荡河道萎缩过程中的河床演变趋势. 泥沙研究, 2003, (1): 10-17.]

[ 7 ] Yue ZC, Ma XY, Tian FC. Analysis on recent water-sediment variation and river regime evolution of Ningxia section of Yellow River. Water Resources and Hydropower Engineering, 2018, 49(2): 117-123. [岳志春, 马晓阳, 田福昌. 黄河 宁夏段近期水沙变化及河势演变分析. 水利水电技术, 2018, 49(2) : 117-123.]

[ 8 ] MacDonald TE, Parker G, Leuthe DP eds. Inventory and analysis of stream meander problems in Minnesota. St Anthony Falls Laboratory, 1991.

[ 9 ] Shields FD, Simon A, Steffen LJ. Reservoir effects on downstream river channel migration. Environmental Conservation, 2000, 27 (1) : 54-66. DOI: 10.1017/s0376892900000072.

[10] Wang YZ, Xia JQ, Zhou MR et al. Characteristics of main channel migration in the braided reach of the Lower Yellow River after the Xiaolangdi Reservoir operation. Advances in Water Science, 2019, 30(2) : 198-209. [王英珍, 夏军强, 周美 蓉, 等. 小浪底水库运用后黄河下游游荡段主槽摆动特点. 水科学进展, 2019, 30(2) : 198-209.]

[11] Jiao EZ ed. The reservoir sediment in the Yellow River. Zhengzhou: Yellow River Water Conservancy Press, 2004. [焦恩 泽. 黄河水库泥沙. 郑州: 黄河水利出版社, 2004.]

[12] Wu BS, Wang GQ, Wang ZY et al. Effects and characteristics of incoming flow and sediment regime on Tongguan elevation. Chinese Science Bulletin, 2004, (14) : 1461-1465. [ 吴保生, 王光谦, 王兆印等. 来水来沙对潼关高程的影响及 变化规律. 科学通报, 2004, (14): 1461-1465.]

[13] Deng AJ, Guo QC, Chen JG. Study of evolution of erosion and deposition in Xiaobeiganliu reach of Yellow River. Journal of Sediment Research, 2011, (2): 27-32. [邓安军, 郭庆超, 陈建国. 黄河小北干流河道冲淤演变规律研究. 泥沙研 究, 2011, (2): 27-32.]

[14] Zheng S, Wu BS. Simulation of sedimentation processes of theXiaobeiganliu reach of the Yellow River and the lower Wei River. Journal of Hydraulic Engineering, 2014, 45(2) : 150-162. [郑珊, 吴保生. 黄河小北干流和渭河下游淤积过程 模拟. 水利学报, $2014, \mathbf{4 5}(2): 150-162$.]

[15] Song ZR, Ma YL, Tang CH. Remote-sensing explanation of the Yangtze River channel in Jiangxi Province. Remote Sensing Technology and Application, 2005, (4) : 415-419. [ 宋志瑞, 马逸麟, 唐春花. 江西长江河道演变遥感解译. 遥感技 
术与应用, 2005, (4) : 415-419.]

[16] Yang C, Cai XB, Wang XL et al. Remotely sensed trajectory analysis of channel migration in Lower Jingjiang reach during the period of 1983-2013. Remote Sensing, 2015, 7(12) : 16241-16256. DOI: 10.3390/rs71215828.

[17] Fletcher C, Rooney J, Barbee M et al. Mapping shoreline change using digital orthophotogrammetry on Maui, Hawaii. Journal of Coastal Research, 2003, (38) : 106-124.

[18] Li X, Zhang LP, Ji CC et al. Spatiotemporal changes of Jiangsu coastline: A remote sensing and GIS approach. Geographical Research, 2014, 33(3) : 414-426. [李行, 张连蓬, 姬长晨等. 基于遥感和 GIS 的江苏省海岸线时空变化. 地理 研究, 2014, 33(3): 414-426.]

[19] Xia JQ, Wu BS, Wang GQ et al. Estimation of bankfull discharge in the Lower Yellow River using different approaches. Geomorphology, 2010, 117(1/2) : 66-77. DOI: 10.1016/j.geomorph.2009.11.007.

[20] Xia JQ, Li XJ, Li T et al. Response of reach-scale bankfull channel geometry to the altered flow and sediment regime in the Lower Yellow River. Geomorphology, 2014, 213: 255-265. DOI: 10.1016/j.geomorph.2014.01.017.

[21] Xie JH, Ding SJ, Wang YH eds. River bed evolution and regulation. Beijing: China Water \& Power Press, 1987. [谢鉴 衡, 丁松君, 王运辉. 河床演变及整治. 北京: 中国水利水电出版社, 1987.]

[22] Wu BS, Wang GQ, Xia JQ et al. Response of bankfull discharge to discharge and sediment load in the Lower Yellow River. Geomorphology, 2008, 100(3/4) : 366-376. DOI: 10.1016/j.geomorph.2008.01.007.

[23] Chien N, Zhang R, Zhou ZD eds. River bed evolution. Beijing: Science Press, 1987. [钱宁, 张仁, 周志德. 河床演变 学. 北京: 科学出版社, 1987.]

[24] Zhao HX ed. Chronicles of the Xiaobeiganliu reach of the Yellow River in Shanxi Province. Zhengzhou: Yellow River Water Conservancy Press, 2002. [ 赵海祥. 山西黄河小北干流志. 郑州: 黄河水利出版社, 2002 . ]

[25] Wang ZY, Li CZ, Wang FX. Effect of Tongguan elevation on the fluvial process of the lower Weihe River. Journal of Hydraulic Engineering, 2004, (9): 1-8. [王兆印, 李昌志, 王费新. 潼关高程对渭河河床演变的影响. 水利学报, $2004,(9): 1-8$.

[26] Lin FF, Xia JQ, Zhou MR et al. Recent response of bankfull channel geometry and flood-discharge capacity in the Lower Jingjiang Reach to upstream and downstream boundary conditions. Journal of Hydraulic Engineering, 2019, 50(5) : 641649. [ 林芬芬, 夏军强, 周美蓉等. 下荆江河槽形态及过流能力调整对上下游边界条件的响应. 水利学报, 2019, 50(5) : 641-649.] 